\title{
REFLUXO VESICOURETERAL EM CRIANÇAS: ARTIGO DE REVISÃO
}

\author{
VESICOURETERAL REFLUX IN CHILDREN: A REVIEW
}

DOI: $10.5380 /$ rmu.v1i1.40682

Juliane Nery ${ }^{1}$, Fábio Augusto Nascimento ${ }^{1}$, Renato Tâmbara Filho ${ }^{1}$

\section{RESUMO}

O Refluxo Vésico-Ureteral é definido como a entidade clínica em que ocorre fluxo retrógrado de urina da bexiga em direção aos ureteres. Conforme o grau do refluxo de urina e a severidade das alterações ocasionadas no sistema coletor renal demonstrado por uretrocistografia miccional, a doença é graduada de I a V, da menor para a maior gravidade. O diagnóstico pré-natal de RVU pode ser presumido através da evidência ultrassonográfica de hidronefrose fetal, enquanto que o diagnóstico pós-natal de RVU geralmente é feito após a ocorrência de infecção de trato urinário ou durante o rastreamento de crianças descendentes de famílias com altas taxas de RVU. A maioria dos pacientes apresentará resolução espontânea do RVU, alguns porém evoluem com infecções de trato urinário de repetição e formações de cicatrizes renais. O tratamento do refluxo vésico-ureteral em crianças é bastante controverso na literatura, variando desde conduta conservadora, com antibioticoprofilaxia de longo prazo, até procedimentos cirúrgicos abertos ou endoscópicos. O objetivo deste trabalho é revisar os principais aspectos relacionados à graduação, manifestações clínicas, diagnóstico, evolução e tratamento de pacientes pediátricos com refluxo vésico-ureteral

Palavras chave: Refluxo vesicoureteral, hidronefrose, sistema urinário.

\section{ABSTRACT}

Vesicoureteral reflux (VUR) is the abnormal retrograde flow of urine from the bladder into the upper urinary tract - ureters and kidneys. According to the extent of the abnormal flow through the urinary tract and the severity of the lesions in the renal collecting system (caused by the reflux), both assessed by voiding cystourethrogram, this pathology may be classified in 5 different grades (I to V).VUR can be suspected prenatally by ultrasound findings of fetal hydronephrosis. Postnatally, on the other hand, this condition is usually diagnosed either after an investigation in an infant presenting with recurrent urinary tract infections (UTIs) or during screening of infants with a positive family history for significant VUR. The majority of infant patients who suffer from VUR will be cured without any intervention as they grow old. However, some of them will experience recurrent UTIs, which may result in kidney scarring. In terms of how to treat children with VUR, it is far from being a consensus among the experts. Some advocate a prophylactic antibiotic therapy only, whereas others believe that a surgical procedure is usually necessary. Our goal is to review the main aspects related to classification, clinical features, diagnosis, complications and treatment of children population affected with VUR.

Key-words: Ureteral Reflux, Hydronephrosis, Urinary Tract.

\author{
1-Universidade Federal do Paraná \\ Contato do Autor / Mail to: \\ Juliane Nery \\ Endereço: Rua Rio Araguari, 2257. Bairro Alto. CEP:82820-040. Curitiba-PR.
}




\section{INTRODUÇÃO}

Uma das principais desordens urológicas pediátricas, o Refluxo Vésico-Ureteral (RVU) é definido como a entidade clínica em que ocorre fluxo retrógrado de urina da bexiga em direção aos ureteres $^{1}$. Acomete aproximadamente $1 \%$ dos neonatos em geral, e até $15 \%$ daqueles com história de hidronefrose pré-natal.

Um dado interessante é que mais de $30 \%$ dos lactentes com infecções de trato urinário (principalmente quando desenvolvem febre no curso da doença) podem ser portadores de $\mathrm{RVU}^{2}$. Daí a importância de todo profissional médico conhecer esta enfermidade, uma vez que seu reconhecimento e manejo tardios podem acarretar consequências danosas ao aparelho urinário da criança.

Crianças brancas são comumente mais afetadas que crianças afrodescendentes ${ }^{1}$. Em relação ao gênero, em geral meninas são mais acometidas (exceto se história pré-natal de hidronefrose, situação em que os meninos são mais afetados que meninas).

No tocante à existência de possível predisposição genética para RVU, os genes que parecem ter papel na patogênese da doença são aqueles que codificam a proteína SLIT2 e o receptor ROBO2, os quais têm papel na formação embriológica do ureter. Além disso, já foi demonstrado que as taxas de RVU são maiores entre gêmeos idênticos que gêmeos fraternos ${ }^{1,2}$.

O RVU ainda pode ser classificado como primário e secundário. A primeira forma é a mais comum, representada pelo inadequado fechamento da junção uretrovesical, com falha deste mecanismo antirrefluxo natural. Em geral, ocorre em crianças com segmento ureteral intravesical encurtado. Há casos que exibem resolução espontânea com o crescimento da criança.

O RVU de etiologia secundária se deve a um aumento na pressão intravesical, ocasionando refluxo da urina para os ureteres. Pode decorrer de anormalidades vesicais anatômicas (e.g. válvula de uretra posterior) ou funcionais (por exemplo, bexiga neurogênica).

O objetivo deste trabalho é revisar os principais aspectos relacionados à graduação, manifestações clínicas, diagnóstico, evolução e tratamento de pacientes pediátricos com refluxo vesico-ureteral.

\section{GRADUAÇÃO}

O International Reflux Study Group desenvolveu um sistema de graduação do RVU de acordo com o grau do fluxo retrógrado de urina e a severidade das alterações ocasionadas no sistema coletor renal demonstrado por uretrocistografia miccional.

De acordo com este sistema, o RVU pode ser graduado em cinco graus, sendo que quanto maior a graduação, maiores os danos ocorrentes no sistema pielo-calicial e mais grave o refluxo urinário. Os casos de RVU classificados como graus I e II são considerados leves; o grau III, moderado e os graus IV e V, grave.

Grau I: O refluxo urinário não alcança a pelve renal e não causa dilatação ureteral.

Grau II: O fluxo urinário alcança a pelve renal, mas não provoca dilatação nos sistema.

Grau III: O refluxo urinário causa dilatação moderada dos ureteres e sistema coletor, associado a leve tortuosidade do sistema pielo-calicial.

Grau IV: O refluxo urinário ocasiona dilatação grave em ureteres e sistema pielo-calicial, com algum grau de tortuosidade ureteral também.

Grau V: O refluxo urinário causa dilatação grosseira de todo o sistema pielo-calicial. Os cálices renais perdem a impressão papilar e algum grau de refluxo intra-renal pode estar presente. Há também significativas dilatação e tortuosidade dos ureteres.

neurológicas ${ }^{9}$, podendo ser resultado da disfunção do sistema nervoso autonômico, periférico ou central ${ }^{6}$. O curso clínico pode ser agudo ou mais arrastado, assim como autolimitado ou progressivo ${ }^{7}$.

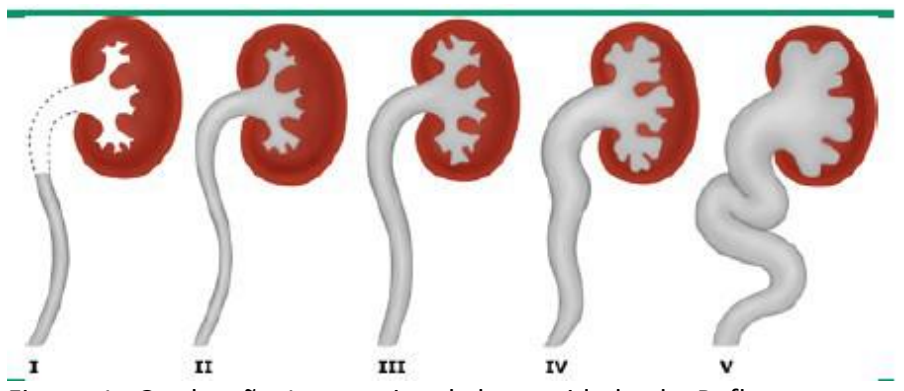

Figura 1: Graduação Internacional da gravidade do Refluxo Vésico-Ureteral conforme a gravidade do fluxo retrógrado de urina em direção ao sistema coletor, evidenciada pelo exame de uretrocistografia miccional. FONTE: International Refux Commitee. Medical Versus

\section{APRESENTAÇÕES CLÍNICAS E DIAGNÓSTICO}

O diagnóstico pré-natal de RVU pode ser presumido através da evidência ultrassonográfica de hidronefrose fetal, a qual é definida por um diâmetro da pelve renal maior ou igual a $4 \mathrm{~mm}$ no segundo trimestre de gestação, ou maior que $7 \mathrm{~mm}$ no terceiro trimestre de gestação. Mesmo assim, estima-se que $17 \%$ das crianças com ultrassonografias normais no período fetal poderão ser diagnosticadas após o nascimento com RVU. 
Há um grande dilema no seguimento diagnóstico dos neonatos com evidencias pré-natais de hidronefrose. Alguns autores advogam o uso de uretrocistografia miccional para todas as crianças que apresentaram este achado na ultrassonografia antenatal. Outros, contudo, defendem o uso da uretrocistografia apenas para as crianças que apresentaram hidronefrose também na ultrassonografia pós-natal.

A base desta discussão advém do fato de a uretrocistografia miccional, exame importante para o diagnóstico de RVU, ser bastante caro e necessitar de pessoal especializado para a sua realização em crianças, além de ser invasivo e um possível causador de lesões e infecções iatrogênicas de trato urinário.

O diagnóstico pós-natal de RVU geralmente é feito após a ocorrência de infecção de trato urinário ou, mais raramente, durante o rastreamento de crianças descendentes de famílias com altas taxas de RVU.

Os métodos de imagem mais utilizados para o diagnóstico pós-natal de RVU são a ultrassonografia de rins e vias urinárias, cistografia com radionuclídeos e uretrocistografia miccional. Este último é o melhor exame diagnóstico, sendo o único que permite graduar o RVU e detectar a presença de refluxo intra-renal.

\section{CURSO CLÍNICO}

A maioria dos pacientes apresentará resolução es-pontânea do RVU. Fatores associados a esta boa evolução incluem idade de diagnóstico abaixo de 12 meses, doença unilateral, refluxo urinário de baixo grau e hidronefrose pré-natal.

Entretanto, há uma parcela de pacientes que evoluem com infecções urinárias frequentes, muitas vezes necessitando de hospitalização e, em outro extremo, com formação de cicatrizes renais.

Em estudo de coorte retrospectivo realizado em Taiwan ${ }^{3}$, idade ao diagnostico acima de 5 anos, RVU de maior grau e maior frequência de infecções de aparelho urinário foram fatores preditivos de formação de cicatrizes renais. Por outro lado, diagnostico de RVU em idade inferior a um ano, histórico de pielonefrite aguda e presença de cicatrizes renais foram fatores que aumentaram o risco de progressão para doença renal crônica.

Estudos mostram que até $60 \%$ dos pacientes diagnosticados com RVU exibem evidências de cicatrizes renais, as quais podem ser congênitas ou decorrer das frequentes infecções urinárias que comumente afetam estas crianças. Quanto mais severo o refluxo urinário, maior a probabilidade de cicatrizes renais. A cintilografia renal estática é mais sensível para detectar tais danos do parênquima renal que a ultrassonografia.
Mesmo assim, ainda não é consenso universal na literatura médica se o RVU é o potente causador de cicatrizes renais, ou se a presença de cicatrizes renais denota possíveis anormalidades congênitas do parênquima renal (displasia, hipoplasia) que podem estar associadas com a ocorrência de outras anormalidades do trato urinário, como o próprio RVU.

Ademais, há que se considerar que o refluxo crônico de urina contaminada para dentro do parênquima renal predispõe o paciente a desenvolver tardiamente hipertensão, proteinúria, glomeruloesclerose focal e doença renal crônica. Mais uma vez, há discordânicas na literatura se é o próprio RVU o causador de todas essas desordens anátomofisiológicas ou se as alterações embriológicas associadas ao RVU são as verdadeiras responsáveis.

O acometimento hepático não é comum nas porfirias. Apenas a protoporfiria eritropoiética, em uma parte pequena de indivíduos $(<10 \%)$ pode cursar com hepatopatia severa, cirrose e colestase ${ }^{9}$. O risco de carcinoma hepatocelular é aumentado na PV, PIA e $\mathrm{CPH} 10$, não estando relacionado com hepatopatia crônica ou aguda.

\section{TRATAMENTO}

As intervenções terapêuticas no RVU visam principalmente à prevenção de infecções urinárias de repetição e de dano parenquimatoso renal, e incluem medidas farmacológicas e cirúrgicas. Além disso, crianças com RVU secundário devem ter a causa base adequadamente manejada.

O correto manejo do RVU é complexo e existem muitas controvérsias entre diferentes autores ${ }^{4}$. Alguns estudos mostram que a vigilância de crianças com RVU e o pronto tratamento de eventuais infecções de trato urinário se mostra tão efetivo quanto o tratamento medicamentoso ou cirúrgico dessa afecção para prevenir danos parenquimatosos renais, especialmente em casos de RVU leve (ie: graus I e II) ${ }^{1,2}$.

Deste modo, é aconselhável consultar a família do paciente afetado, expondo-lhes os tratamentos disponíveis e seus potenciais benefícios e complicações, realizando a escolha da opção terapêutica em conjunto.

\section{Tratamento medicamentoso}

A principal medida terapêutica farmacológica para RVU consiste na administração diária de antibioticoprofilaxia. Essa medida baseia-se nas premissas de que a maioria das crianças apresentará resolução espontânea do $\mathrm{RVU}$, e que o uso contínuo de antibióticos mantém a urina estéril. O refluxo de urina livre de contaminação não tem um potencial tão grande de causar danos renais. 
Os medicamentos mais usados incluem trimetoprim (sozinho ou associado ao sulfametoxazol) e nitrofurantoína. A dose preconizada é metade a um quarto da dose usada no tratamento da infecção de trato urinário, e deve ser administrada antes de dormir. O uso de amoxicilina e cefalosporinas deve ser desencorajado, uma vez que pode gerar organismos resistentes, exceto em crianças abaixo dos 2 meses de vida (idade em que os outros antibióticos supracitados podem ter efeitos adversos mais sérios).

Há muitas controvérsias no tocante ao tempo certo de parar a administração de antibioticoprofilaxia. Alguns estudos recomendam cessar tal medida terapêutica em crianças que já adquiriram o controle esfincteriano e que tenham um refluxo de baixo grau, e que preferencialmente estejam livres de infecção de trato urinário nos últimos 6 a 9 meses.

\section{Tratamento medicamentoso}

O procedimento cirúrgico visa a corrigir anatomicamente a junção ureterovesical, de modo a não permitir o refluxo de urina para os ureteres. Pode ser aberto ou endoscópico.

\section{Reimplantação Cirúrgica Aberta:}

Esse procedimento tem alta taxa de sucesso, chegando a $99 \%$,independentemente do grau de RVU. A abordagem usada pode ser transvesical ou extravesical, e os ureteres são reimplantados na bexiga através da tuneilização de um segmento ureteral dentro do detrusor. $O$ paciente requer cateterização vesical para drenagem no pós-operatório, e em geral permanece poucos dias no hospital.

\section{Tratamento Endoscópico:}

O tratamento endoscópico para RVU tem ganhado popularidade devido em grande parte aos seus benefícios ao pacientes no que tange à menor necessidade de hospitalização pós-operatória, alta taxa de eficácia, baixa taxa de complicações ${ }^{5}$. A Injeção Transuretral Suburete-ral é um procedimento ambulatorial primeiramente realizado em 1984. Consiste na injeção de um copolímero (dextrano/ácido hialurônico) por baixo da mucosa da junção ureterovesical através de um cistoscópio. Acredita-se que tal abordagem ocasione mudança na fixação do ureter, corrigindo o RVU. As taxas de sucesso são maiores que $75 \%$.

Essa abordagem também é custo-efetiva, comparada à antibioticoprofilaxia de longo prazo $^{5}$ e, em estudo realizado por Garge e cols ${ }^{6}$, mostrou melhorar a qualidade de vida dos pacientes, se refletindo em maior bem estar emocional e aumento da capacidade de aprendizagem.

\section{SEGUIMENTO CLÍNICO}

O monitoramento clínico de crianças que mantiveram tratamento medicamentoso ou conduta expectante é necessário para detectar precocemente a ocorrência de infecção de trato urinário (ITUs), a resolução possível do RVU e o estado geral de saúde e desenvolvimento da criança.

A avaliação geral inclui medidas de peso, altura e pressão arterial periodicamente, além de uroculturas e urinálises cada vez que surgirem sinais e sintomas sugestivos de infecções de trato urinário ou quadro febril de causa indeterminada.

O monitoramento do RVU é feito com uretrocistografias miccionais a cada 12 a 24 meses. A ultrassonografia renal pode ser realizada anualmente com o intuito de avaliar a presença de lesões parenquimatosas renais. Em pacientes com graus maiores de RVU (acima de III), preconiza-se o uso de cintilografia com DMSA para a procura de cicatrizes renais (porém há controvérsias quanto ao intervalo que este exame deve ser realizado com este objetivo).

\section{CONCLUSÃO}

O refluxo vésico-ureteral é uma entidade clínica complexa em sua fisiopatologia e manejo. Há ainda muitas controvérsias na literatura sobre como deve ser feita a abordagem diagnóstica do paciente suspeito (por exemplo, neonatos com evidências antenatais de hidronefrose) e, também, no tocante à estratégia terapêutica a ser abordada.

Devido aos potenciais riscos de causar desordens do aparelho urinário, muitas vezes irreversíveis e catastróficas, fica clara a necessidade de conhecer esta desordem para a realização de diagnóstico precoce e adequado tratamento.

Por fim, ressalta-se que, independentemente da escolha da conduta para o paciente portador de RVU, é de suma importância evitar a ocorrência de infecções de trato urinário e tratá-las prontamente caso ocorram. Ainda mais importante que isso é a monitorização e, principalmente, a prevenção de formação de cicatrizes renais.

\section{REFERÊNCIAS BIBLIOGRÁFICAS}

1. MCLORIE G, HERRIN JT. Presentation, diagnosis and clinical course of vesicoureteral reflux. Disponível em www.uptodate.com. 2013:1-26Acesso em 06/04/2013.

2. MCLORIE G, HERRIN JT. Management of vesicoureteral re-flux. Disponível em www.uptodate.com. 2013:1-26Acesso em 06/04/2013.

3. CHEN MJ, CHENG HL,CHIOUYY. Risk Factors for Renal Scar-ring and Deterioration of Renal Function in Primary Vesico-Ureteral Reflux Children: A Long-Term Follow-Up Retrospective Cohort Study. Plos One. 2013; 8(2): 1-9. 


\section{REVISTA MÉDICA DA UFPR}

4. COOPER CS. Individualizing Management of Vesicoureteral Reflux. Nefro-Urol-Mon. 2012; 4(3): 530-534.

5. KIM JW.Endoscopic Treatment of Vesicoureteral Reflux in Pediatric Patients. Korean J Pediatr. 2013; 56(4): 145-150.

6. GARGE S, MENOM P, RAO KNM, BHATTACHARYA A, ABRAR L et al. Vesicoureteral Reflux: Endoscopic Therapy and impact on healthy related quality of life. J Indian Assoc Pediatr Surg. 2013; 18(1): 11-15. 